\title{
Pregnancy Outcomes in Infertile Women with Polycystic Ovaries following Intracellular Sperm Injection
}

\author{
Chiman K. Mawlood, MBChB, MSc, PhD \\ College of Medicine, Hawler Medical University, Erbil44001, Kurdistan Region, Iraq
}

\begin{abstract}
Polycystic ovary syndrome (PCOS) is a complex endocrine condition characterized by polycystic ovarian morphology (PCOM), oligo- or anovulation, and clinical or biochemical hyperandrogenism. Intracytoplamic sperm injection (ICSI) has been used extensively in treatment of infertile women with PCOS. In Iraq, pregnancy outcomes in PCOS patients following ICSI have yet to be evaluated. This study has therefore been conducted to define pregnancy outcomes in Iraqi PCOS patients as well as to define oocyte meiotic competence and normality following ovarian hyperstimulation. Although high doses of gonadotropin were used in infertile women with normal ovaries, the numbers of retrieved oocytes and estradiol peak levels were higher in patients with PCOM and PCOS than in patients with normal ovaries $(P \leq 0.01)$. Wealso found that PCOM women have higher antral follicle count (AFC) than did PCOS women $(P=0.0001)$. Moreover, significant high mean numbers of immature, mature, and degenerated oocytes were observed in PCOS and PCOM patients in comparison to those in control patient, which might be due to the high bulk of AFC and consequently higher numbers of oocyte recovered in PCOS or PCOM. As for ICSI outcomes, PCOS or PCOM patients had significantly higher fertilization, grade one embryo, embryo transfer and implantation, pregnancy, and live birth rates than did control patients. It is concluded that infertile women with PCOS or PCOM have higher pregnancy rates than do infertile women with unexplained or tubal-type infertility following ICSI.
\end{abstract}

Keywords: infertility, polycystic ovary syndrome, in vitro fertilization, intracytoplasmic sperm injection.

\section{Introduction}

Polycystic ovary syndrome (PCOS) is recognized as one of the most common endocrine/metabolic disorders of women. Its prevalence depends in part upon the diagnostic criteria used to define the disorder. The prevalence of PCOS under National Institutes of Health (NIH), Rotterdam, and Androgen Excess and PCOS Society criteria was 6.1, 19.9 and $15.3 \%$, respectively[1]. The Rotterdam criteria state that two out of the following three criteria should be present in the diagnosis of PCOS: oligo-anovulation, clinical and/or biochemical hyperandrogenism, and polycystic ovaries of 12 or more follicles measuring 2-9 $\mathrm{mm}$ in diameter in the whole ovary and/or increased ovarian volume $\left(>10 \mathrm{~cm}^{3}\right)$. Although polycystic ovary morphology and PCOS overlap, and PCOM is included in the definition of PCOS, diagnosis of patients with PCOM depends only on observing 12 or more follicles measuring $2-9 \mathrm{~mm}$ in diameter in the whole ovary and/or increased ovarian volume $\left(>10 \mathrm{~cm}^{3}\right)$ according to the Rotterdam criteria[2].

In Iran, 12 studies were designed to evaluate the prevalence rate of infertility, and a meta-analysis was performed to integrate the findings of these separate studies. The average rate of infertility was $10.9 \%$ [3]. According to another study conducted by the Egyptian Fertility Care Society, and sponsored by the World Health Organization (WHO), infertility in Egypt affects 12 percent of couples. Of these women, 4.3 percent suffer from primary infertility and 7.7 percent suffer from secondary infertility [4]. In a cohort study from Duhok, Iraq, from January 2000 to May 2001, the causes of infertility were studied for 250 couples. The investigators found that $77.2 \%$ of infertile couples had primary infertility and $22.8 \%$ had secondary infertility. Male infertility was found in $36.8 \%$ of the cases[5]. Only few studies were done to estimate the prevalence of PCOS in the Middle East. Two large Iranian studies found the prevalence of PCOS to be around 7\% [6-7].To the best of our knowledge, pregnancy outcomes in infertile women with PCOS following assisted reproductive technology have yet to be studied.

Intracytoplasmic sperm injection (ICSI) has become the mainstay in the treatment of PCOS. The ability of ICSI to achieve fertilization regardless of sperm quality has made this technique an ideal procedure to treat severe male factor infertility as well as PCOS. In Iraq, most of PCOS women are treated with ICSI. Moreover, oocyte maturation and normality in polycystic ovarian patients are not fully defined. This study was therefore designed to define the pregnancy outcomes, including oocyte maturation and degeneration rate, in infertile women with PCOM or PCOS undergoing hyperstimulation and ICSI.

\section{Materials and Methods}

\section{Setting}

This study was conducted at the Center of Fertility and IVF, Maternity Teaching Hospital, in Erbil, Iraq. This center was established in April 2010 and is the main referral center for infertility in Erbil state. For this prospective clinical comparative study, patients were recruited from April $1^{\text {st }}$, 2012 to April $1^{\text {st }}, 2013$.

\section{Patients and ethical approval}

Among 488 infertile women that were qualified for this study, 190 women were confirmed to have PCOS based on Rotterdam criteria, 50 women with PCOM (i.e. only polycystic ovary without the clinical or biochemical changes associated with PCOS), and 248 infertile women with no 


\section{International Journal of Science and Research (IJSR) \\ ISSN (Online): 2319-7064}

Index Copernicus Value (2015): 78.96 | Impact Factor (2015): 6.391

evidence of PCOS or PCOM. The latter were considered the control patients, and they had tubal factor or unexplained infertility. Patients with PCOS, PCOM, or normal ovaries had similar age, duration of infertility, body mass index, and smoking habit $(\mathrm{P}>0.05)$. Inclusion criteria included women with primary or secondary infertility, 19-46 year old, and who were referred for assisted reproduction to have their first ICSI treatment cycle.Exclusion criteria included infertile women with endocrine abnormalities related to primary hyperprolactinaemia, thyroid dysfunction, Cushing's syndrome, and/or congenital adrenal hyperplasia. Infertile women having previous IVF or ICSI cycle attempts were also excluded. This study was approved by the Research Ethics Committee of the College of Medicine/Hawler Medical Universityat June 25 $5^{\text {th }}, 2011$. Informed consents were obtained from all participants.

\section{Ultrasonography and PCOS diagnosis}

For ultrasound screening, a transvaginal ultrasonographic screening with $6.5 \mathrm{MHz}$ vaginal transducer (GE LOGIQ P3 Expert/Logic P3, probe destination E8CS/E8C, USA) was used. According to Rotterdam-PCOS criteria, patients with PCOS were diagnosed if at least two of the following criteria were observed: oligomenorrhoea/anovulation, defined by a delayed menses ( $>35$ days) or less than eight spontaneous hemorrhagic episodes/year; clinical hyperandrogenism, defined by hirsutism using modified Ferriman-Gallwey score of $\geq 8$ or biochemical hyperandrogenism of total testosterone $>0.481 \mathrm{ng} / \mathrm{ml}$; and/or PCOM on ultrasonography of more than 12 follicles of $2-9 \mathrm{~mm}$ per ovary. In addition, women without oligomenorrhea/amenorrhea and hyperandrogenism but with 12 or more follicles/ovary, measuring $2-9 \mathrm{~mm}$ in diameter, were diagnosed with PCOM [8-9].The transvaginal ultrasonic screening was performed during the follicular phase, second or third day of the cycle.

\section{Ovarian hyperstimulation and ICSI}

The ovarian stimulation was started 2-3 cycles after the patient's first visit to the center. Patients were started with 75-300 IU of gonadotropin based on age, body mass index (BMI), basal FSH, and patient response. Ovarian response was monitored with serum $\mathrm{E}_{2}$ measurement and transvaginal ultrasonography startingon day six of the cycle. A single intramuscular injection of highly purified hCG of 10000IU (hCG; Choriomon ${ }^{\circledR}$, IBSA-InstitudBiochimique, Switzerland) was administered to patients when at least 2-3 follicles became more than $17-18 \mathrm{~mm}$ in diameter. Transvaginal oocyte retrieval was conducted $34-36 \mathrm{hr}$ after the hCG administration. Oocytes were first washed in GMops plus medium (Vitrolife, Sweden) and incubated in GIVF Plus medium supplemented with human serum albumin (Vitrolife, Sweden) at $37^{\circ} \mathrm{C}$ and $6 \% \mathrm{CO}_{2}$ in humidified air for $2 \mathrm{hr}$. Oocytes were then denuded and evaluated for meiotic maturation and morphology. Briefly, oocytes that showed a nuclear membrane and intact nucleolus were classified as meiotically immature oocytes at the germinal vesicle stage $(\mathrm{GV})$. Oocytes that had undergone $\mathrm{GV}$ breakdown, but did not have a polar body, were classified as metaphase I (MI) oocytes, whereas those with first polar bodies were classified as metaphase II (MII) oocytes [10]. As for oocyte morphological normality, oocytes with smooth granular or transparent cytoplasm, single polar body, appropriate zona pellucida thickness, and proper perivitelline space (PVS) were considered normal and consequently used in ICSI. Conversely, oocyteswith coarse granular, non-homogeneous, dark (brownish-blackish), or fragmented cytoplasm; distorted oolemma;or non-spherical (irregular shape) with or without large PVS were considered degenerated [10-13].

Semen was collected by masturbation after an abstinence period of three days. Thirty to forty minutes were allowed for semen to liquefy at $37^{\circ} \mathrm{C}$ before seminal analysis according to World Health Organization criteria[14].On day of insemination, Sperm preparation was carried out using the swim-up method.In cases of severe poor semen parameters, spermatozoa were prepared by mixing equal volumes of GMOPS + medium and semen, centrifuging twice, and resuspending the pellet in small volume of media before injection. Inseminated oocytes were washed and incubated in groups of 3 oocytes in $40 \mu \mathrm{l} \mathrm{G1}+$ medium droplet (Vitrolife, 101128, Sweden) covered with mineral oil. The oocytes were then cultured for 18-20h before evaluation for fertilization under a high power inverted microscope. Fertilization was considered normal when two clearly distinct pronuclei were observed plus the $2^{\text {nd }}$ polar body. If a single pronucleus was observed, a second evaluation was carried out after an addition $4 \mathrm{hr}$ [15]. Embryos were cultured at $37^{\circ} \mathrm{C}$ and $6 \% \mathrm{CO}_{2}$ in humidified air before transferred on day three after fertilization. On average 3-4 embryos of high gradeswere selected and transferred using G2+ media (vitrolife, Sweden) and embryo transfer catheters (Cook,KJETS-7019-SIVF,Austrila).

\section{Luteal phase support}

Women were treated orally with $10 \mathrm{mg}$ tablet of synthetic progesterone (dydrogesterone, duphaston ${ }^{\circledR}$, Abbott, USA), tid, and $400 \mathrm{mg}$ pessaries of natural progesterone (cyclogest $^{(}$, Actavis, UK) once a day. Both luteal support therapies were started one day after the oocyte retrieval and continued for two weeks. If the $\beta$-hCG assay showed a positive result after two weeks from the transfer, both medications were continued for an additional 12-16 weeks.

\section{Biochemical and clinical pregnancy and ICSI outcomes}

Patients were considered to have positive biochemical pregnancy when $\beta$-hCG was $>20 \mathrm{IU} / 1$. The test was repeated 2 days later to confirm the results.Patients were considered to have clinical pregnancies when a gestation sac and a viable fetal heart beat were observed five weeks from the transfer. Early pregnancy loss or miscarriage was defined as the loss of a pregnancy before 20 weeks.

\section{Results}

\section{Clinical data of control, PCOM, PCOS patients following ovarian hyperstimulation}

All control, PCOM, or PCOS patients underwent ovarian hyperstimulation with a starting dose of 75-300 IU of gonadotropin. Patients with PCOS or PCOM required less number of gonadotropin doses, as defined by the total number of vials used, than did control patients, $25.6 \pm 0.6$ and $25.9 \pm 1.3$ vs.33.3 \pm 0.6 , respectively $(\mathrm{P}<0.0001$, Table 1$)$. However, the numbers of days of stimulation among control, PCOM, or PCOS patients were comparable $(\mathrm{P}>0.05)$. 


\section{International Journal of Science and Research (IJSR) \\ ISSN (Online): 2319-7064}

Index Copernicus Value (2015): 78.96 | Impact Factor (2015): 6.391

Interestingly, low levels of estradiol at day of hCG injection were observed in control patients in comparison to PCOS or PCOM patients, $\mathrm{P}<0.0001$ or $\mathrm{P}=0.01$, respectively. In addition, more oocytes were retrieved in PCOM or PCOS patients than in control patients, $10.2 \pm 0.6$ or $10.6 \pm 0.5 \mathrm{vs}$. $6.4 \pm 0.3$, respectively, $\mathrm{P}<0.0001$.

\section{Antral follicle count in $\mathrm{PCO}$ patients}

The AFC mean numbers were evaluated between only PCOM and PCOS patients. AFC in control infertile women was not used in this comparison since by diagnosis criteriaall control infertile women have AFC less than 12 follicles.Patients with PCOM have higher mean numbers of AFC than patients with PCOS, $26.3 \pm 0.4$ vs. $22.7 \pm 0.6$, respectively, $(\mathrm{P}=0.0001$, Fig. 1).

\section{Oocyte meiotic maturation and degeneration ratesin control, PCOM, and PCOS patients \\ Retrieved oocytes were then scored for their maturational status based on the criteria mentioned earlier. Patients with PCOS demonstrated higher mean number of GV oocytes than did control patients ( $8.9 \pm 1.2 v s .4 .2 \pm 1.0, \mathrm{P}=0.01$, Fig. 2$)$. Patients with PCOS also showed higher mean number of MI oocytes than did control patients ( $7.3 \pm 1.5$ vs. 2.6 \pm 0.9 , $\mathrm{P}=0.02$, Fig. 3). As for MII oocyte rates, both PCOS and PCOM patients have higher mean number of MII oocytes than did control patients $(\mathrm{P}<0.0001$, Fig. 4. More degenerated oocytes were recovered in PCOS patients than in control or PCOM patients, $6.3 \pm 1.1$ vs. $1.5 \pm 0.6$ or $1.6 \pm 1.0$, $\mathrm{P}<0.0001$ or $\mathrm{P}=0.005$, respectively (Fig. 5).}

\section{Fertilization and embryonic development and transfer rate in control, PCOM, and PCOS patients}

Fertilization rates among control, PCOM, and PCOS patients were comparable ( $\mathrm{P}=0.1$, Table 2$)$. However, high numbers of embryos were obtained in PCOS or PCOM patients than in control patients $(\mathrm{P} \leq 0.003)$. In addition, more high quality embryos of grade one were observed in PCOM $(\mathrm{P}=0.015)$ or $\operatorname{PCOS}(\mathrm{P}<0.0001)$ than in control patients, $2.8 \pm 0.3$ or $3.2 \pm 0.2$ vs. $2.1 \pm 0.1$, respectively. Similar to grade one embryos, more embryos were transferred in PCOM $(\mathrm{P}<0.0001)$ or PCOS (P0.001) patients than in control patients (Table 2). However, the implantation rate was similar among all groups $(\mathrm{P}>0.05)$.

\section{Pregnancy outcomes per cycle following ICSI in control, PCOM, or PCOS patients}

Patients with PCOM had higher rates of pregnancy/cycle than did control or PCOS patients $56 \%$ vs. $30.6 \%$ or $38.9 \%$, $\mathrm{P}=0.001$ or $\mathrm{P}=0.03$, respectively (Table 3 ). Patients with PCOS also had higher pregnancy rate than did control patients; however, that increase was not significantly different $(\mathrm{P}=0.07)$. Similarly, patients with PCOM or PCOS were also observed to have higher levels of clinical pregnancy/cycle than did control patents, $\mathrm{P}=0.014$ or $\mathrm{P}=0.035$, respectively. Moreover, the live birth rate per cycle was also higher in PCOM or PCOS patients than in control patients, $\mathrm{P}=0.006$ or $\mathrm{P}=0.015$, respectively. Both rates of twin/cycle and miscarriage/pregnancy among control, PCOM, or PCOS patients were similar $(\mathrm{P}>0.05)$.
Pregnancy outcomes per embryo transfer following ICSI in control, PCOM, or PCOS patients

Patients with PCOM had higher rates of pregnancy/embryo transfer (ET) than did patients with normal ovaries, $57.1 \mathrm{vs.}$ 34.2 , respectively ( $\mathrm{P}=0.003$, Table 4$)$. Patients with PCOS had higherrate of pregnancy/ET than did control patients; however, that increase was not significantly different $(\mathrm{P}=0.08)$. Similarly, patients with PCOM or PCOS were also observed to have higher levels of clinical pregnancy/ET than did control patents $(\mathrm{P}=0.04)$. Moreover, the live birth rate per ET was also higher in PCOM or PCOS patients than in control patients, 36.7 or 31.2 vs. 20.6 , respectively, $\mathrm{P}=0.017$ for both.

\section{Discussion}

This study demonstrates that although high doses of gonadotropin were used in infertile women with normal ovaries, the numbers of retrieved oocytes and E2 peak levels were higher in patients with PCOM and PCOS more than in patients with normal ovaries. This might be due to the fact that patients with PCOS or PCOM have high antral follicle count (AFC), and by inclusion criteria, patients with AFC $>12$ follicles/ovary were classified as PCOM or PCOS patients. Interestingly, basal follicle number had a positive linear correlation with recovered oocytes and basal and peak E2 and a negative linear correlation with both number of ampules of administered gonadotropin and days of stimulation [16-18]. This means in patients with normal ovaries, a set of follicles, from a follicular pool of less than 12 follicles/ovary, will develop and ovulate during the ovarian hyperstimulation. However, in patients with PCOS or PCOM, more follicles will have the chance to develop and ovulate. This aids to explain why less numbers of oocytes were recovered in control patients despite of high doses of gonadotropin administered. An additional reason, clinicians usually administer gonadotropins in PCOS/PCOM patients with precaution, because thosepatients are sensitive for exogenous gonadotropins and may easily develop ovarian hyperstimulation syndrome[19]. This can create a non-favorable bias regarding the number of administered gonadotropin doses in PCOS or PCOM patients. Moreover, the stimulation periods of time were similar in all patient groups. From experience, this might me due to the fact that follicular response in PCOS and PCOM patients tends to be slow but explosive at later stages.

It has been agreed that women with AFC greater than 12 follicles (measuring 2-9 $\mathrm{mm}$ in diameter) are considered to have polycystic ovaries. In this study, we found that PCOM women have higher AFC than PCOS women. This might due to the fact that PCOM women are solely classified depending on the AFC, i.e patients with greater than 12 follicles. However, it is not necessary that all PCOS patients have AFC greater than 12 follicles, because there are four phenotypes of PCOS where they may have or not have AFC greater than 12 follicles. In other words, not all of phenotypes of PCOS are diagnosed based on the presence of high AFC. For instance, although PCOS patients with phenotype A, C, and D are diagnosed partially based on the presence of high AFC, PCOS patients with phenotype B are not classified based on AFC. The latter is diagnosed based on the presence of both oligomenorrhea and 


\section{International Journal of Science and Research (IJSR) \\ ISSN (Online): 2319-7064}

Index Copernicus Value (2015): 78.96 | Impact Factor (2015): 6.391

hyperandroginisim and does not include AFC[2]. Therefore, in our study although all PCOM patients $(100 \%)$ had high AFC, only $82.6 \%$ of our PCOS patients had high AFC. This may explain the high levels of AFC in PCOM patients over PCOS patients.

We observed high mean numbers of immature and mature oocytes in PCOS and PCOM patients in comparison to those in control patient. Although the increase in mean number of mature oocytes in PCO patients would be expected as those patients ovulated more oocytes due to their high bulk of AFC, the recovery of immature and degenerated oocytes is questionable. Patients with PCOS or PCOM have ovarian hyperandrogenism and hyperinsulinemia. As for hyperandrogeism, hyperanodgenic oocytes were observed to associate with abnormal gene expression profiles that involve signal transduction, transcription, chromosome alignment, and segregation during mitosis andmeiosis[20]. Moreover, cumulus cells from women with PCOS were characterized by abnormal expression of many growth factors that are known to play a role in oocyte maturation and developmental competence [21-22].In addition, a dosedependent inhibition of meiotic maturation was observed in both cumulus-enclosed and cumulus-denuded murine oocytes following incubation with testosterone for $18 \mathrm{~h}$ [23]. In addition to hyperandrogenism, and as stated earlier, recovery of immature and degenerated oocytes in PCOS patients could also be due to hyperinsulinemia. Insulin sensitivity in PCOS patients is intrinsically impaired with abnormal post-receptor signal transduction; thereby, resulting in reduced insulin-mediated glucose uptake in oocytes and impaired glucose-insulin homeostasis in oocytes[24-25]. This impairment in insulin sensitivity and hyperinsulinemia in PCOS patients enhance also androgen productionleading to arrest of cell proliferation and follicle growth [26-27]. These data clearly explain that ovarian hyperandrogenism, recognized in PCO patients, contributes to oocyte incompetence and atresia.

Studies regarding the impact of PCOS or PCOM on oocyte competence are conflicting [28-33]. Many factors could have been responsible on this contradiction such as ovulation induction program, patient age and ethnicity [34], and BMI. The present study shows high pregnancy rates in patients with PCOS or PCOM. Hperinsulinemia, heperandrogenism, metabolic syndrome have contributed to arrest several growing follicles at the small antral stage but unlikely to compromise further follicular growth and oocyte meiotic maturation after the initiation of ovarian hyperstimulation. We also report that patients with PCOS or PCOM had favorable ICSI outcomes; fertilization, grade one embryo, embryo transfer and implantation, pregnancy, and live birth rates, which might be due to greater numbers of follicles available and consequently oocytes retrieved in PCOS and PCOM patients than in control patients with tubal infertility factor. In addition, PCOS and PCOM patients received low doses of gonadotropin in comparison to control patients. Exogenous administration of gonadotropin has been observed to negatively impact embryo quality [35]. The utilization of low doses of gonadotropin plus the recovery of great numbers of MII oocytes might have reduced the impact of high incidence of degeneratedand immature oocytesrateson pregnancy outcomes in PCOS and
PCOM patients. Moreover, the lack of association between PCOS and embryonic aneuploidy[36], and the similar chromosomal normality of unfertilized oocytes from patients with or without PCSO [37], might have also contributed to the high pregnancy outcomes in PCSO or PCOM patients observed in this study.

In conclusion, this study is in agreement with other reports indicating high pregnancy rates in PCOS patients following assisted reproductive technology [38-41]. Moreover, oocyte meiotic maturation and degeneration rates in Iraqi patients with PCOS or PCOM were also evaluated.

\section{Conflicts of Interest}

The authors declare no conflicts of interest.

\section{References}

[1] March WA, Moore VM, Willson KJ, et al. The prevalence of polycystic ovary syndrome in a community sample assessed under contrasting diagnostic criteria. Hum Reprod 2010;25:544.

[2] Rotterdam ESHRE/ASRM-Sponsored PCOS Consensus Workshop Group. Revised 2003 consensus on diagnostic criteria and long-term health risks related to polycystic ovary syndrome. FertilSteril 2004;81:1925.

[3] Parsanezhad ME, Jahromi BN, Zare N, Keramati P, Khalili A, Parsa-Nezhad M. J Womens Health, Issues Care 2013, 2:6 http://dx.doi.org/10.4172/23259795.1000121.

[4] Sallam HN, Ezzeldin F, Agameya AF, Rahman AF, El-Garem Y. Defining poor responders in assisted reproduction. Int J FertilWomens Med 2005;50:11520.

[5] Razzak AH, Wais SA.The infertile couple: a cohort study in Duhok, Iraq.East Mediterr Health J. 2002;8(23):234-8

[6] Mehrabian F, Khani B, Kelishadi R, Ghanbari E: The prevalence of polycystic ovary syndrome in Iranian women based on different diagnostic criteria. Polish J Endocrinol 2011,62:238-42.

[7] Tehrani FR, Simbar M, Tohidi M, Hosseinpanah F, Azizi F. The prevalence of polycystic ovary syndrome in a community sample of Iranian population. ReprodBiolEndocrinol 2011;9:39.

[8] Balen AH, Conway GS, Kaltsas G, Techatraisak K, Manning PJ, West C, Jacobs HS. Polycystic ovary syndrome: the spectrum of the disorder in 1741 patients. Hum Reprod 1995;10:2705-12.

[9] Franks S. Controversy in clinical endocrinology: diagnosis of polycystic ovarian syndrome: in defense of the Rotterdam criteria. J ClinEndocrinolMetab 2006;91:786-9.

[10] Veeck LL. Atlas of the Human Oocyte and Early Conceptus, $1^{\text {st }}$ edn. Williams \& Wilkins, Maryland 1986.

[11] Donahue RP. Maturation of the mouse oocyte in vitro. I. Sequence and timing of nuclear progression. J ExpZool 1968;169:237-49.

[12] Ebner T, Moser M, Sommergruber M, Tews G.Selection based on morphological assessment of

\section{Volume 6 Issue 1, January 2017}




\section{International Journal of Science and Research (IJSR) \\ ISSN (Online): 2319-7064}

Index Copernicus Value (2015): 78.96 | Impact Factor (2015): 6.391

oocytes and embryos at different stages of preimplantation development: a review. Hum Reprod Update 2003;9:251-62.

[13] Swain JE, Pool TB. ART failure: oocyte contributions to unsuccessful fertilization. Hum Reprod Update 2008; 14:431-46.

[14] World Health Organization (WHO) revised glossary of ART terminology. FertilSteril 2009;92:1520-24.

[15] Staessen C, Janssenswillen C, Devroey P, Van Steirteghem AC. Cytogenetic and morphologic observation of single pronucleated human oocytes after in-vitro fertilization. Hum Reprod 1993;8:221-3.

[16] Frattarelli JL, Lauria-Costab DF, Miller B, Bergh PA, Scott Jr. RT, Basal antral follicle number and mean ovarian diameter predict cycle cancellation and ovarian responsiveness in assisted reproductive technology cycles. FertilSteril 2000;74:512-7.

[17] Himabindu Y, Sriharibabu M, Gopinathan K, Satish U, Louis TF, Gopinath P. Anti-mullerian hormone and antral follicle count as predictors of ovarian response in assisted reproduction. J Hum ReprodSci 2013; 6(1):27-31.

[18] Tomas C, Nuojua-Huttunen S, Martikainen $\mathrm{H}$. Pretreatment transvaginal ultrasound examination predicts ovarian responsiveness to gonadotrophins in in-vitro fertilization. Hum Reprod 1997;12(2):220-3.

[19] Vause TD, Cheung AP, Sierra S, Claman P, Graham J, Guillemin JA, et al. Ovulation induction in polycystic ovary syndrome. J ObstetGynaecol Can 2010; 32:495502 .

[20] Wood JR, Dumesic DA, Abbott DH, Strauss JF 3rd. Molecular abnormalities in oocytes from women with polycystic ovary syndrome revealed by microarray analysis.J ClinEndocrinolMetab 2007;2:705-13.

[21] Abbott DH, Barnett DK, Bruns CM, Dumesic DA. Androgen excess fetal programming of female reproduction: a developmental aetiology for polycystic ovary syndrome? Hum Reprod Update 2005;11:35774.

[22] Haouzi D, Assou S, Monzo C, Vincens C, Dechaud H, HamamahS.Altered gene expression profile in cumulus cells of mature MII oocytes from patients with polycystic ovary syndrome.Hum Reprod 2012;12:3523-30.

[23] Anderiesz C, Trounson AO. The effect of testosterone on the maturation and developmental capacity of murine oocytes in vitro.Hum Reprod 1995;9:2377-81.

[24] Balen AH, Conway GS, Homburg R, Legro RS. Polycystic Ovary Syndrome. A Guide to Clinical Management. Taylor and Francis; London 2005;47-67.

[25] Dumesic DA, Abbott DH. Implications of polycystic ovary syndrome (PCOS) on oocyte development. Seminreprod med 2008;26:53-61.

[26] Franks S, Gilling-Smith C, Watson H, et al. Insulin action in the normal and polycystic ovary. EndocrinolMetabClin North Am 1999;28:361-78.

[27] Franks S, Mason H, Willis D. Follicular dynamics in the polycystic ovary syndrome. Mol Cell Endocrinol 2000;163:49-52.

[28] BeydounHA,Stadtmauer L,Beydoun MA, Russell H, Zhao Y, Oehninger S.Polycystic Ovary Syndrome, Body Mass Index and Outcomes of Assisted
Reproductive Technologies. Reprod Biomed Online 2009;18(6): 856-63.

[29] Beydoun HA, Stadtmauer L, Zhao Y, Russell H, Matson DO, Oehninger S.Impact of polycystic ovary syndrome on selected indicators of in vitro fertilization and intracytoplasmic sperm injection treatment success.J Womens Health (Larchmt) 2009;18(5):71723.

[30] Engmann L, Maconochie N, Sladkevicius P, Bekir J, Campbell S, Tan SL.The outcome of in-vitro fertilization treatment in women with sonographic evidence of polycystic ovarian morphology.Hum Reprod 1999;14(1):167-71.

[31] Esinler I, Bayar U, Bozdag G, Yarali H. Outcome of intracytoplasmic sperm injection in patients with polycystic ovary syndrome or isolated polycystic ovaries.FertilSteril 2005;84(4):932-7.

[32] Sahu B, Ozturk O, Ranierri M, SerhalP.Comparison of oocyte quality and intracytoplasmic sperm injection outcome in women with isolated polycystic ovaries or polycystic ovarian syndrome.Arch GynecolObstet 2008;277(3):239-44.

[33] Mikkelsen AL, Lindenberg S. Morphology of in-vitro matured oocytes: impact on fertility potential and embryo quality.Hum Reprod 2001;16(8):1714-8.

[34] Palep-Singh M, Picton HM, Vrotsou K, Maruthini D, BalenAH.South Asian women with polycystic ovary syndrome exhibit greater sensitivity to gonadotropin stimulation with reduced fertilization and ongoing pregnancy rates than their Caucasian counterparts.Eur J ObstetGynecolReprodBiol 2007;134(2):202-7.

[35] Van der Auwera I, D'Hooghe T. Superovulation of female mice delays embryonic and fetal development. Hum Reprod 2001;16:1237-44.

[36] Gleicher N, Weghofer A, Barad DH. Anti-Müllerian hormone $(\mathrm{AMH})$ defines, independent of age, low versus good live-birth chances in women with severely diminished ovarian reserve. FertilSteril 2010;94:28247.

[37] Sengoku K, Tamate K, Takuma N, Yoshida T, Goishi $\mathrm{K}$, Ishikawa $\mathrm{M}$. The chromosomal normality of unfertilized oocytes from patients with polycystic ovarian syndrome. Hum Reprod 1997;12(3):474-7.

[38] Eldar-Geva T, Ben-Chetrit A, Spitz IM, Rabinowitz R, Markowitz E, Mimoni $\mathrm{T}$, et al. Dynamic assays of inhibin B, anti-Mullerian hormone and estradiol following $\mathrm{FSH}$ stimulation and ovarian ultrasonography as predictors of IVF outcome. Hum Reprod 2005;20:3178-83.

[39] Fallat ME, Siow Y, Marra M, Cook C, Carrillo A. M€ullerian-inhibiting substance in follicular fluid and serum: a comparison of patients with tubal factor infertility, polycystic ovary syndrome, and endometriosis. FertilSteril 1997;67:962-5.

[40] Hazout A, Bouchard P, Seifer DB, Aussage P, Junca AM, Cohen-Bacrie P. Serum anti-Mullerian hormone/Mullerian-inhibiting substance appears to be a more discriminatory marker of assisted reproductive technology outcome than follicle-stimulating hormone, inhibin B, or estradiol. FertilSteril 2004;82:1323-9.

[41] La Marca A, Orvieto R, Guilini S, Jasonni VM, Volpe A, DeLeo V. Müllerian inhibiting substance in women with polycystic ovary syndrome: relationship with hormonal and metabolic characteristics. FertilSteril 2004;82:970-2. 


\section{International Journal of Science and Research (IJSR) \\ ISSN (Online): 2319-7064 \\ Index Copernicus Value (2015): 78.96 | Impact Factor (2015): 6.391}

\section{Tables}

Table 1: Clinical data in control, PCOM, and PCOS patients following ovarian hyperstimulation

\begin{tabular}{|c|c|c|c|c|}
\hline Clinical data & Control & PCOM & PCOS & $P$ value \\
\hline Total dose of gonadotropin & $33.3 \pm 0.6^{\mathrm{a}}$ & $25.9 \pm 1.3^{\mathrm{a}}$ & $25.6 \pm 0.6^{\mathrm{b}}$ & $\mathrm{P}<0.0001$ \\
\hline No. of stimulation days & $10.1 \pm 0.1^{\mathrm{a}}$ & $10.4 \pm 0.3^{\mathrm{a}}$ & $10.3 \pm 0.1^{\mathrm{a}}$ & $\mathrm{P}>0.05$ \\
\hline $\mathrm{E}_{2}$ at day of hCG & $1256.7 \pm 52.2^{\mathrm{a}}$ & $1714.1 \pm 144.4^{\mathrm{b}}$ & $2082.0 \pm 88.4^{\mathrm{b}}$ & $\mathrm{P} \leq 0.01$ \\
\hline No. of retrieved oocyte & $6.4 \pm 0.3^{\mathrm{a}}$ & $10.2 \pm 0.6^{\mathrm{b}}$ & $10.6 \pm 0.5^{\mathrm{b}}$ & $\mathrm{P}<0.0001$ \\
\hline
\end{tabular}

Data are presented as mean \pm SEM. Values with different superscripts along each row are significantly different using the oneway ANOVA test followed by the Bonferroni post hoc test. Control patients were 248, polycystic ovary morphology (PCOM) patients were 50, and polycystic ovary syndrome (PCOS) patients were 190. E2: estradiol two; hCG: human chorionic gonadotropin.

Table 2: Fertilization rate and embryonic development and transfer in control, PCOM, and PCOS

\begin{tabular}{|l|c|c|c|c|}
\hline Outcomes & Control & PCOM & PCOS & $P$ value \\
\hline Average fertilization rate/patient & $70.0 \pm 2.0^{\mathrm{a}}$ & $70.0 \pm 3.0^{\mathrm{a}}$ & $80.0 \pm 2.0^{\mathrm{a}}$ & $\mathrm{P}=0.1$ \\
\hline Average No. of Embryo/patient & $4.1 \pm 0.2^{\mathrm{a}}$ & $6.1 \pm 0.5^{\mathrm{b}}$ & $6.3 \pm 0.3^{\mathrm{b}}$ & $\mathrm{P} \leq 0.003$ \\
\hline Average Grade one-embryo/patient & $2.1 \pm 0.1^{\mathrm{a}}$ & $2.8 \pm 0.3^{\mathrm{b}}$ & $3.2 \pm 0.2^{\mathrm{b}}$ & $\mathrm{P} \leq 0.015$ \\
\hline Average no. of embryo transfer/patient & $2.7 \pm 0.1^{\mathrm{a}}$ & $3.3 \pm 0.1^{\mathrm{b}}$ & $3.0 \pm 0.1^{\mathrm{b}}$ & $\mathrm{P} \leq 0.001$ \\
\hline Average implantation rate/patient & $40.0 \pm 10.0^{\mathrm{a}}$ & $40.0 \pm 10.0^{\mathrm{a}}$ & $40.0 \pm 2.0^{\mathrm{a}}$ & $\mathrm{P}=0.7$ \\
\hline
\end{tabular}

Data are presented as mean \pm SEM except for fertilization and implantation which are both of mean \pm SEM percent. Values with different superscripts along each row are significantly different using the one-way ANOVA test followed by the Bonferroni post hoc test. Control patients were 248, polycystic ovary morphology (PCOM) patients were 50, and polycystic ovary syndrome (PCOS) patients were 190.

Table 3: Intracellular sperm injection outcomes of ICSI per cycle in control, PCOM, and PCOS patients

\begin{tabular}{|l|c|c|c|c|}
\hline ICSI outcomes & Control & PCOM & PCOS & $P$ value \\
\hline Pregnancy/cycle & $30.6^{\mathrm{a}}$ & $56.0^{\mathrm{b}}$ & $38.9^{\mathrm{a}}$ & $\mathrm{P} \leq 0.03$ \\
\hline Clinical pregnancy/cycle & $25.0^{\mathrm{a}}$ & $42.0^{\mathrm{b}}$ & $34.2^{\mathrm{b}}$ & $\mathrm{P} \leq 0.035$ \\
\hline Live birth/cycle & $18.5^{\mathrm{a}}$ & $36.0^{\mathrm{b}}$ & $28.4^{\mathrm{b}}$ & $\mathrm{P} \leq 0.015$ \\
\hline Twin/live birth & $13.0^{\mathrm{a}}$ & $27.8^{\mathrm{a}}$ & $20.4^{\mathrm{a}}$ & $\mathrm{P}>0.05$ \\
\hline Miscarriage/pregnancy & $25.0^{\mathrm{a}}$ & $14.3^{\mathrm{a}}$ & $14.9^{\mathrm{a}}$ & $\mathrm{P}>0.05$ \\
\hline
\end{tabular}

Data are presented as averge percent of total number of patients. Values with different superscripts along each row are significantly different where $\mathrm{P}<0.05$ using Pearson's chi-square test of independence. Control patients were 248 , PCOM (polycystic ovary morphology) patients were 50, and PCOS (polycystic ovary syndrome) were 190. ICSI:Intracellular sperm injection.

Table 4: Outcomes of ICSI per embryo transfer in control, PCOM, and PCOS patients

\begin{tabular}{|l|c|c|c|c|}
\hline ICSI outcomes & Control & PCOM & PCOS & $P$ value \\
\hline Pregnancy/ET & $34.2^{\mathrm{a}}$ & $57.1^{\mathrm{b}}$ & $42.8^{\mathrm{ab}}$ & $\mathrm{P}=0.003$ \\
\hline Clinical pregnancy/ET & $27.8^{\mathrm{a}}$ & $42.9^{\mathrm{b}}$ & $37.6^{\mathrm{b}}$ & $\mathrm{P}=0.04$ \\
\hline Live birth/ET & $20.6^{\mathrm{a}}$ & $36.7^{\mathrm{b}}$ & $31.2^{\mathrm{b}}$ & $\mathrm{P}=0.017$ \\
\hline
\end{tabular}

Data are presented as percent of total number of patients. Values with different superscripts along each row are significantly different using the Pearson's chi-square test of independence. Control patients with embryo transfer (ET) were 222, PCOM (polycystic ovary morphology) patients with ET were 49, and PCOS (polycystic ovary syndrome) with ET were 173. 


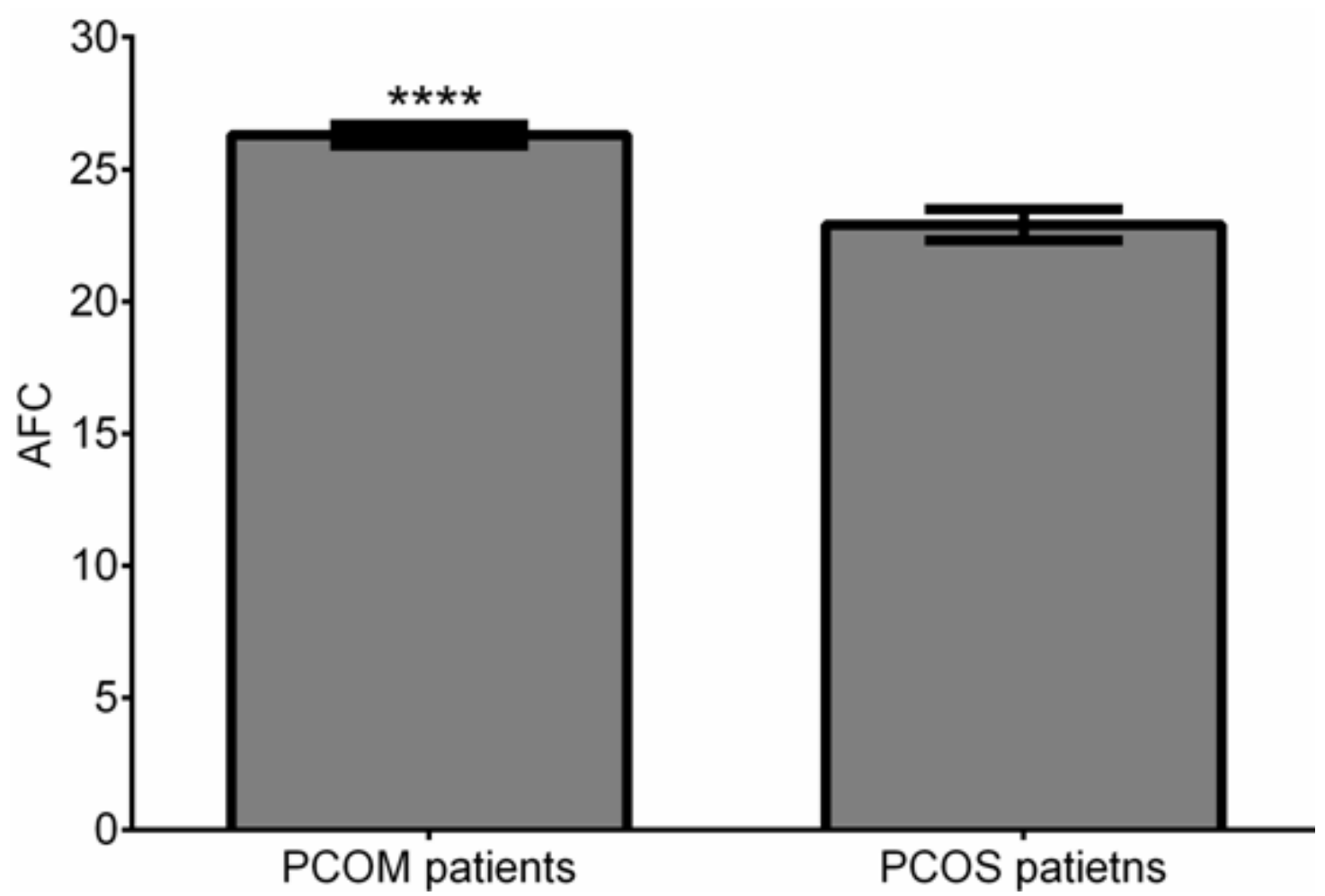

Figure 1: The antral follicle count (AFC) mean difference between patients with polycystic ovary morphology (PCOM) or polycystic ovary syndrome (PCOS). Values with asterisks are significantly different where $\mathrm{P}=0.0001$ usingthe independentsample t-test.

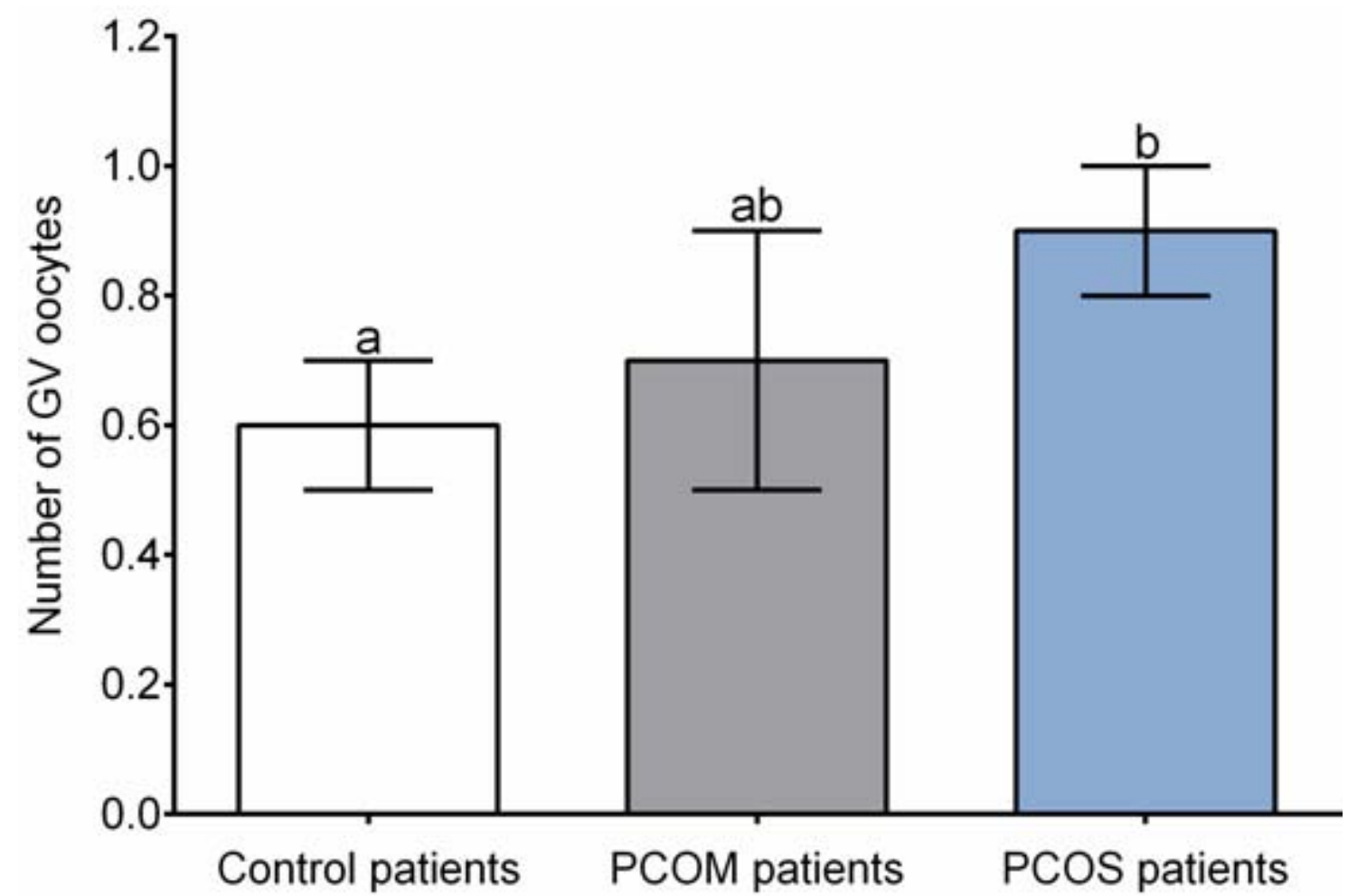

Figure 2: Germinal vesicle (GV) oocyte rates among control ( $\mathrm{n}=248)$, PCOM (50), and PCOS (190) patients. Values with different superscripts are significantly different where $\mathrm{P}=0.04$ using the one-way ANOVA test followed by the Bonferroni post hoc test. Data are presented as mean \pm SEM. 


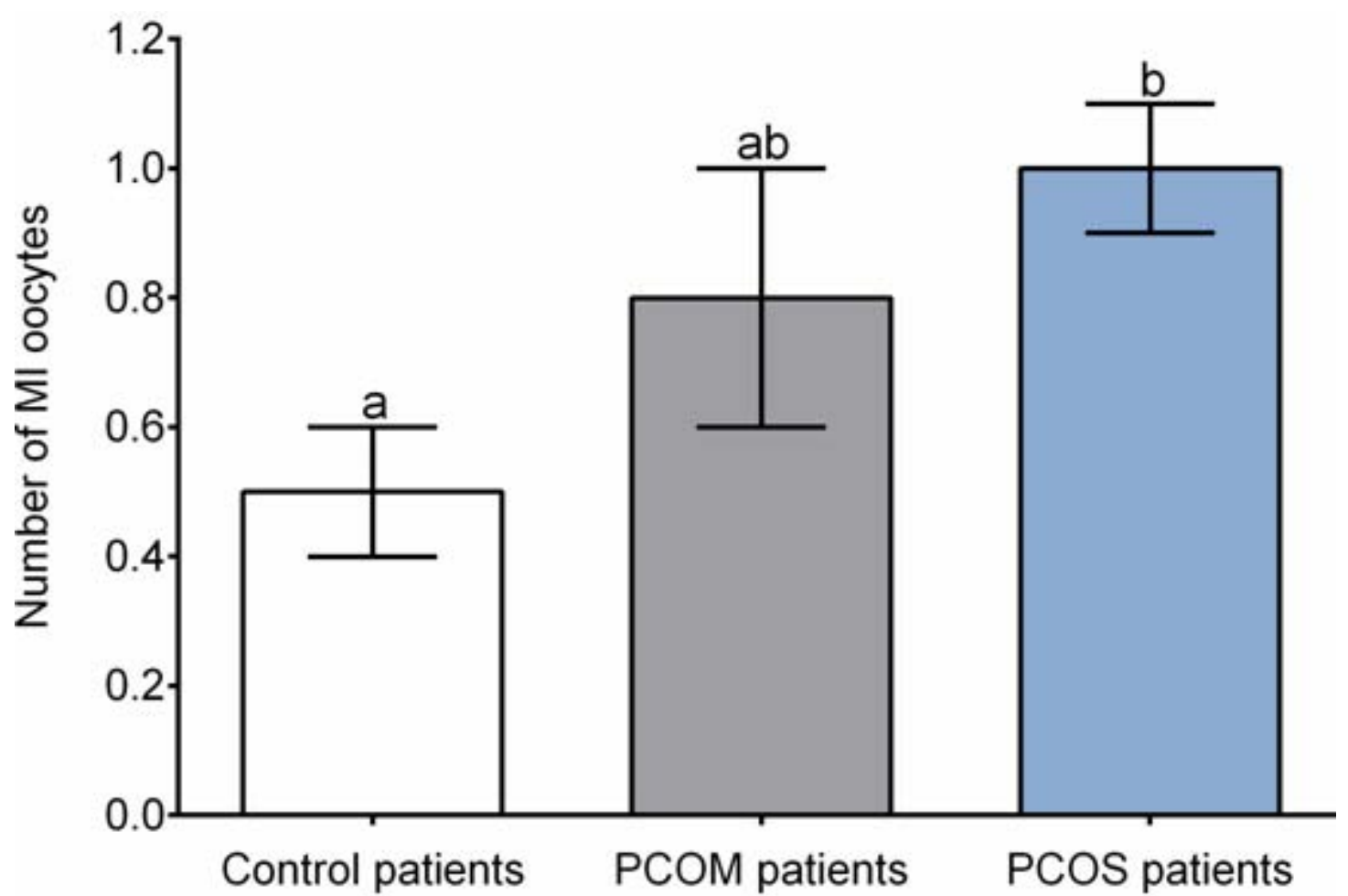

Figure 3: Metaphase I (MI) oocyte rates among control ( $\mathrm{n}=248)$, PCOM (50), and PCOS (190) patients. Values with different superscripts are significantly different where $\mathrm{P}<0.0001$ using the one-way ANOVA test followed by the Bonferroni post hoc test). Data are presented as mean \pm SEM.

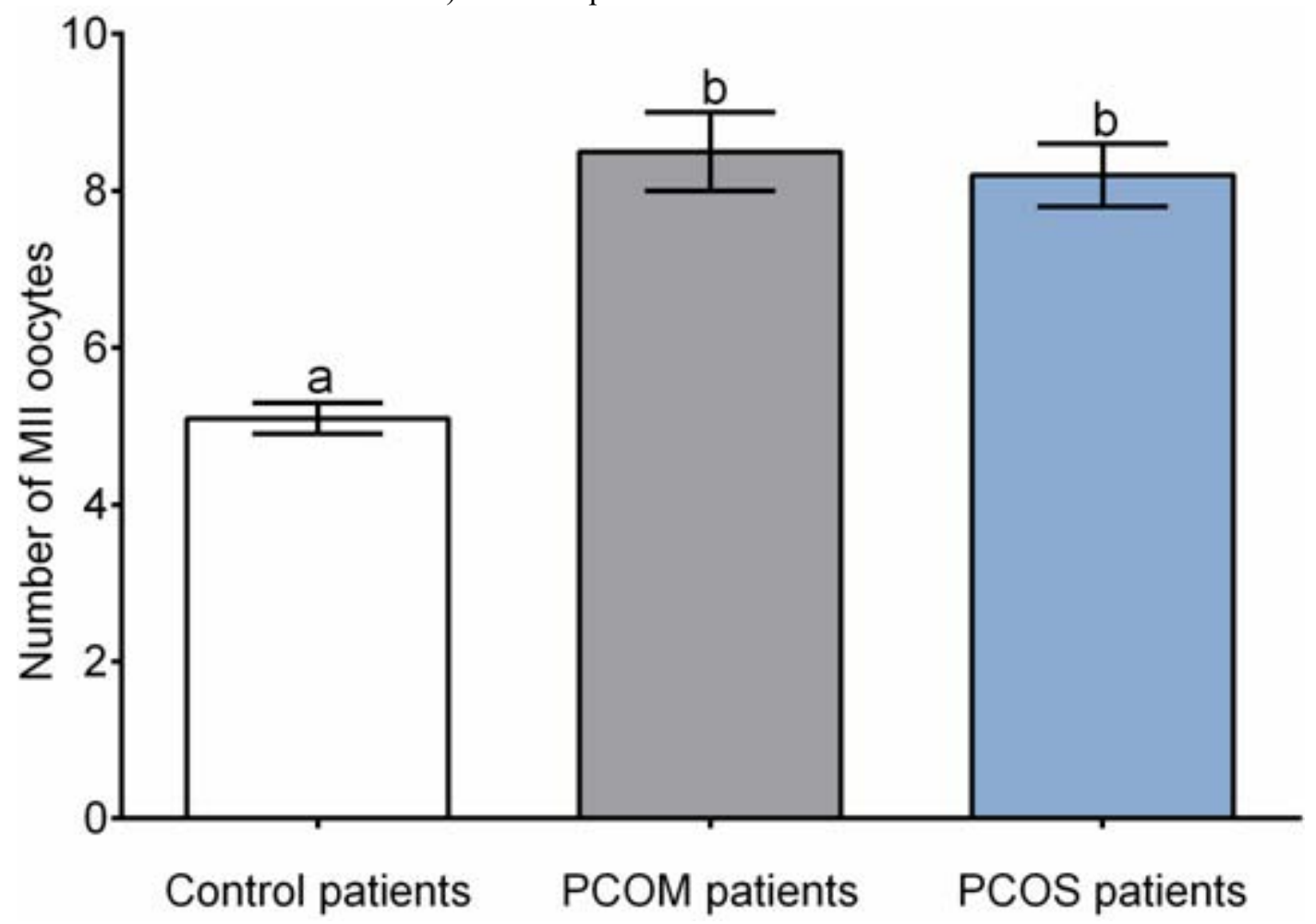

Figure 4: Metaphase II (MII) oocyte rate among control ( $\mathrm{n}=248)$, PCOM (50), and PCOS (190) patients. Values with different superscripts are significantly different where $\mathrm{P}<0.0001$ using the one-way ANOVA test followed by the Bonferroni post hoc test. Data are presented as mean \pm SEM. 


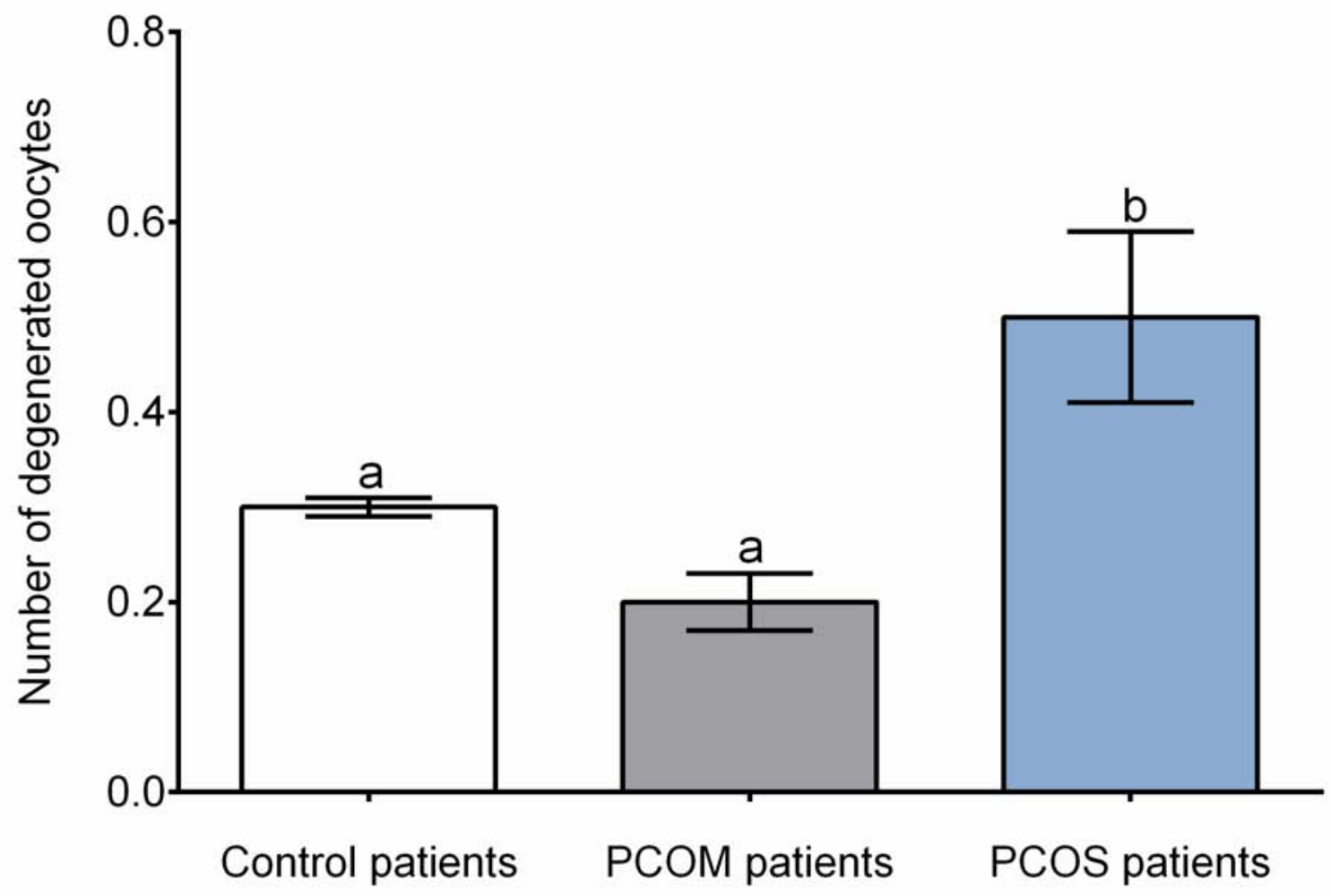

Figure 5: Degenerated oocyte rate among control ( $\mathrm{n}=248)$, PCOM (50), and PCOS (190) patients. Values with different superscripts are significantly different where $\mathrm{P} \leq 0.04$ usingthe one-way ANOVA test followed by the Bonferroni post hoc test . Data are presented as mean \pm SEM.

\section{Author Profile}

Chiman Khudur Mawlood has $\mathrm{MBChB}$ and $\mathrm{PhD}$ in in vitro fertilization. She is a graduate and also a lecturer in the College of Medicine, Hawler Medical University in Erbil, Kurdistan, Iraq. She is also a consultant gynecology and director of Yad IVF Center in Erbil. Chiman has four children who are also graduates and students in the Medical field. 